\title{
ТЕКУЩИЙ НЕФТЯНОЙ КРИЗИС: ОСНОВНЫЕ КОНФЛИКТНЫЕ ЛИНИИ И ПЕРСПЕКТИВЫ РАЗРЕШЕНИЯ
}

\begin{abstract}
Аннотация. Предметом исследования статьи является потенциал демпинга нефтяных цен в мировом политическом прочессе. Нефть, как стратегический продукт, часто использовалась как политическое оружие и инструмент давления в международных отношениях. Политический фактор энергетических кризисов менялся в зависимости от текущего состояния мировой политики. Особенностью современного момента развития мира является высокий уровень силы, конфликтности и наличие глубоких противоречий между ведущими странами. В таких условиях манипулирование нефтяными ценами достаточно эффективный способ достижения необходимых геополитических целей. Методологическую основу исследования составили системный, исторический, социологический, сравнительный методы исследования, метод ситуативного анализа, а также общенаучные подходы обобщения, индукции и дедукции. В результате исследования автор пришел к выводу, что геополитические интересы основных участников ценового конфликта 2014 года предопределяют политические договоренности между странами-лидерами добычи нефтти по дестабилизаиии нефртяного рынка. Стремление Европы снизить зависимость от российских энергоносителей и желание США сохранить мировое лидерство привели к двойному удару по нефтедобывающему сектору России и по ее экономике в целом. Текущий кризис преобразует устаревшую политическую систему, приведет к серьезным изменениям в мироустройстве, новым договоренностям и новой расстановке сил на мировой арене. Санкции против России имеют основания стать долгосрочными, но у страны есть все шансы преодолеть последствия кризиса при адекватной вызовам политике государства.
\end{abstract}

Ключевые слова: международные отношения, внешняя политика, нефтяной кризис, демпинг нефтяных чен, геополитика, сотрудничество, антироссийские санкции, политика импортозамещения, изменения в мироустройстве, коллективная система безопасности.

Review: The subject of the research is the dumping potential of oil prices in the global political process. Oil as a strategic product has been frequently used as a political weapon and the instrument of pressure in the international relations. The political factor of energy crises has been changing depending on the current condition of the world policy. In this situation the manipulation of oil prices is a rather effective way of achievement of the necessary geopolitical aims. The methodology of the research is based on the systems method, the historical, sociological and comparative methods, the method of situation analysis, and the general scientific methods of generalization, induction and deduction. The author concludes that geopolitical interests of the main participants of the oil prices conflict of 2014 predetermine the political agreements between the leaders of oil production aimed at the destabilization of oil market. The aspiration of Europe for the decrease of its dependence on Russian energy resources and the desire of the USA for the preservation of its world leadership led to a double damage for Russian oil-producing industry and economy. The current crisis will transform the obsolete political system, and will lead to serious changes in the world order, new agreements and a new balance of power on the international scene. Sanctions against Russia may be long-term, but the country has all the chances to overcome the consequences of the crisis with the support of the government policy adequate to the challenges.

Keywords: changes in the world order, policy of import substitution, anti-Russian sanctions, cooperation, geopolitics, dumping of oil prices, oil crisis, foreign policy, international relations, collective security system.

$\mathrm{O}$ бвал мировых цен на нефть в 2014 году привел к экономическим проблемам в ряде добывающих стран. Разворачивающийся нефтяной кризис не стал чем-то новым в современной мировой истории, однако каждый энергетический кризис индивидуален и имеет свои отличительные особенности. Происходящие сегодня события отличаются от трудностей в энергетике во время кризиса 2008 года, начавшегося с обру- шения фондового рынка, распространившегося на экономику всех стран мира и в результате снизившего стоимость нефти. Текущий кризис был спровоцирован падением цены на нефть и создал проблемы только в странах-экспортерах.

Снижение цены на энергоносители ведет к перераспределению доходов от добывающих стран к потребителям. Импорт дешевой нефти стимулирует экономику, повышает экономическую актив- 
ность, пополняет бюджет, снижает государственную задолженность. При этом больше выиграют те, кто закупает нефти больше. Это в первую очередь Индия, Китай, Япония и европейские страны. А перед поставщиками низкая цена ставит проблему выживания. Особенно страдают те, кто тратит нефтяные доходы, а не накапливает их. Кризис может спровоцировать в их энергодобывающих отраслях слияние компаний, закрытие буровых установок, замораживание проектов и инвестпрограмм. Но кто-то, стремясь сохранить свою долю рынка, продолжит качать нефть с убытками или минимальной прибылью [9].

Возникновение энергетического кризиса, ввиду его сложного многогранного характера, зависит от соотношения разнообразных факторов. Нефть с самого начала своего интенсивного использования находилась не только в центре мировой экономики, но также политики и развития технологий [3]. Экономическими предпосылками текущего падения цены на нефть стало замедление развития мировой экономики, прежде всего таких крупных потребителей как Китай, Евросоюз, Япония, снизившее потребность в энергии и приведшее к превышению предложения над спросом, наличие рекордных мировых стратегических запасов нефти, укрепление доллара на фоне роста американской экономики, начало восстановления добычи в Ливии, продажа нефти вооруженными группировками Ирака и Сирии, не имеющими возможности официально торговать, по бросовым ценам и др. Кроме того, спекулятивный фактор ускорил падение цены на нефть путем стремительного вывода денег из фьючерсных контрактов [6].

Большое влияние на мировые нефтяные цены оказал технологический прорыв в области добычи сланцевых углеводородов. США, первые применившие эти технологии, достигли больших объемов добычи, что позволило им удовлетворить внутренний спрос за счет собственной нефти и начать экспансию на внешние рынки. Также, благодаря новым техническим достижениям, все больше расширяется применение альтернативной и атомной энергетики.

Но доминирующая роль в развитии энергетических кризисов всегда принадлежала политическому фактору, отражающемуся в состоянии мировой политики. Особенностью современного момента является наличие глубоких противоречий в международных отношениях. Сегодня мир характеризуется высоким уровнем силы и конфликтности, снижением роли ООН в урегулировании миро- вых проблем, активизацией радикального ислама, усложнением взаимоотношений мировых лидеров и кризисом доверия между ними. Наиболее ярко накопившиеся проблемы проявились в событиях на Украине. Здесь столкнулись геополитические интересы США, ЕС и России. Толчком к жесткой конфронтации стало присоединение Крыма к России, воспринятое Западом как военная агрессия, угрожающая международному устройству мира. В результате против России были введены санкции, как инструмент давления, с целью заставить ее пойти на уступки. Началась эскалация противостояния, не принесшая эффекта ни в политическом, ни в военном, ни в экономическом плане. Нанести серьезный ущерб российской экономике смогли только падающие цены на нефть. Предположить только экономическую природу такого резкого скачка стоимости нефти в существующей международной обстановке представляется недальновидным.

Манипулирование нефтяными ценами достаточно эффективный способ достижения необходимых геополитических целей в современных условиях. Политический потенциал демпинга нефтяных цен огромен и не раз уже использовался в мировом политическом процессе. Нефть, как стратегический продукт, является политическим оружием, инструментом давления. Контроль над крупными нефтяными месторождениями, транспортными коридорами позволяет решать свои национальные экономические и политические задачи и управлять многими мировыми процессами. При совпадении интересов различные игроки энергорынка на основе политических договоренностей могут координировать усилия по управлению нефтяными ценами. Это вполне реально, поскольку современный рынок предложения нефти регулируется одной стороной - производителями, и решающая роль в этом процессе принадлежит ОПЕК. Особенно на фоне объективных экономических причин дестабилизировать рынок несложно. Конечно, такие договоренности не становятся объектом гласности, но анализ мотивов и конфликтных линий разворачивающихся событий наглядно демонстрирует политическую подоплеку происходящих событий.

Главным действующим лицом, повлиявшим на падение цен, уже традиционно стала Саудовская Аравия, увеличившая добычу вместе с Кувейтом, что способствовало нефтяному изобилию на рынке. Эр-Рияд достаточно мотивирован для целенаправленного демпинга цен. Сегодня в меняющейся мировой конъюнктуре перед страной, 
являющейся мировым лидером по добыче нефти и ее экспорту, встала задача сохранения своей доли на нефтяном рынке. Главной угрозой ее доминированию в экспорте стало развитие сланцевой энергетики в США. В результате ухода США с рынка, как крупного импортера, и увеличения американского экспорта нефтепродуктов Саудовская Аравия потеряла часть своих покупателей. Но у сланцевой нефти есть уязвимое место - ее достаточно высокая себестоимость. В этой связи низкие цены при существующих технологиях добычи могут подорвать рост американского производства, способствуя сворачиванию программ бурения. Кроме того в рамках обостряющейся конкуренции за нефтяной рынок Азии Эр-Рияд надеется с помощью низких цен сохранить своего стратегического партнера и крупного покупателя - Китая, находящегося в условии кризисных тенденций в собственной экономике [1].

Еще одной давней внешнеполитической целью Саудитов, на достижение которой может быть направлено понижение цены на нефть, является ослабление экономик их противников Ирана и Сирии. Во-первых, это сотни лет длящаяся борьба между суннитами и шиитами, где суннитская Саудовская Аравия противостоит распространению шиитского ислама из Ирана, Сирии. Во-вторых, Эр-Рияд рассматривает Тегеран, как главного экономического конкурента в регионе. Иран является крупным независимым нефтяным игроком, хотя и входит в ОПЕК. И, несмотря на санкции Запада по ограничению его присутствия на мировом энергетическом рынке, Республика продолжает оставаться важным экспортером нефти. Особенно сейчас, когда наметился прогресс в достижении соглашения по иранской ядерной программе и возможна отмена санкций, у страны появляется возможность усилить свои позиции на мировой арене. Россия уже активизирует экономические отношения с Ираном. Москва готова поставить зенитно-ракетные комплексы C-300, которые носят оборонительный характер и значительно усилят ПВО страны. Что, по словам В.В.Путина, станет сдерживающим фактором и послужит стабилизации обстановки в регионе на фоне разворачивающихся событий в Йемене. В этих условиях Эр-Рияд заинтересован в противодействии укреплению экономики Тегерана за счет нефтяных цен.

С другой стороны, удешевление нефти ослабит собственный бюджет Саудовской Аравии, что может привести к сокращению расходов на социальные программы и увеличит риск протестных настроений в стране. В этой связи есть версия существования сговора между Эр-Риядом и Вашингтоном, основанная на зависимости Саудовской Аравии от США, который является ее стратегическим партнером и гарантом стабильности, и который восполнит потери своего союзника, поскольку у Америки есть свои интересы в дестабилизации нефтяного рынка. Конечно, низкие цены на нефть снижают рентабельность американской сланцевой энергетики. Но она и без того имеет ряд недостатков - быстрое истощение скважин, необходимость постоянного нового бурения, экологические проблемы, высокую себестоимость. Возможно, исходя из неопределенного будущего сланцевой нефти, Америка готова пожертвовать ею на данном этапе ради достижения более глобальных целей.

К таким целям относится сохранение США в качестве единственного мирового лидера, о чем не раз заявлял Барак Обама. У страны есть на это объективные основания: крупнейшая в мире экономика и сильная армия, исходя из этих условий, Америка осуществляет экономическую и политическую экспансию на всех континентах. Однако мир не готов быть сырьевым придатком США. Ceгодня формируется многосторонняя и многополярная модель взаимодействия между странами. В этой связи для сохранения своей гегемонии перед Америкой стоят две важные задачи, требующие безотлагательного решения: снижение огромного внешнего долга и сохранение доллара в качестве мировой резервной валюты, являющейся основным экспортным товаром США и обеспечивающим ей мировое господство. И нефть в этих вопросах играет важную роль, поскольку цена на нее традиционно устанавливается в долларах. Однако у ряда стран есть желание перейти на национальные валюты при расчетах за энергоресурсы, что может реально нанести ущерб Соединенным Штатам. Подобные попытки жестко пресекаются Америкой. В планы США может входить разорение низкими ценами таких крупных поставщиков, не подвластных им, как Иран, Венесуэла, Россия. Борьбу за Иран Америка ведет давно. Контроль над иранской нефтью даст США возможность в союзе с Саудовской Аравией распоряжаться почти половиной мировых запасов этого сырья, диктовать условия на нефтяном рынке и получить рычаг давления на импортеров [10].

С другой стороны нефтяной ценовый кризис укрепил доллар, спрос на него увеличился вдали от реальной американской экономики. Самим США увеличение курса американской валюты к другим 
национальным валютам дает возможность скупать активы на подешевевшем мировом фондовым рынке, частично уменьшая свой государственный долг, серьезной головной боли американской экономики.

Погасить долги, не подкрепленные реальными активами, у страны сегодня нет возможности. Гипотетическая девальвация доллара, как способа уйти от долгов, уничтожит страну и создаст хаос во всем мире. Именно поэтому Россия выступает за создание нескольких резервных мировых валют, как гарантии финансовой стабильности в мире. Но Вашингтон избрал другой путь решения этой проблемы. Для стимулирования развития американской экономики нужны мощные рынки, и самым привлекательным для этой цели является европейский рынок и в первую очередь его энергетический сектор, занятый сегодня Россией и другими поставщиками энергоресурсов. В этой связи США стремится вынудить Европу разорвать отношения с РФ и переориентировать экономику на Америку. Для этого используется обвал цен на нефть, запугивание европейцев русской угрозой, создание из Украины барьера между Россией и ЕС. При этом интересы самой Европы американцами не рассматриваются. Отказ ЕС от российских углеводородов и переход на американский сланцевый газ приведут к потерям для европейской экономики. Но Европа не является самостоятельным образованием, а находится под политическим и военным контролем Вашингтона и вынуждена следовать его курсом.

Однако есть и собственно европейские политические мотивы, ведущие к конфронтации с Россией. Поэтому европейские санкции против России отражают не только результат нажима со стороны США, но и их собственные интересы. Европа всегда рассматривала Россию как идеологического противника и геополитического соперника. Политика сдерживания России времен холодной войны продолжается и сегодня. И решающую роль в этом играет позиция Германии, являющейся лидером Евросоюза. ЕС развязывает ожесточенную борьбу за зоны пересекающихся интересов с Россией, стремясь ограничить ее влияние в Средней Азии, в Закавказье, на Балканах, ослабить ее, разрушив экономические и политические связи с внешним миром [7].

Практикуя «двойные стандарты» и используя информационную войну, Запад старательно участвует в создании из России образа врага, подготавливая почву для разрыва отношений и оправдания своих действий перед лицом собственного бизнеса и гражданского общества. Европа сегод- ня воюет с Россией руками Украины, нацелив ее на выполнение задачи по изоляции России. И на пути к этой цели обвал нефтяных цен очень кстати сильно ударил по российской экономике. А для Европы дешевая нефть является положительным моментом, увеличивающим конкурентоспособность ее промышленности [4].

В текущем кризисе в наиболее сложной ситуации оказалась Россия, попав под двойной удар со стороны экономических санкций и низких нефтяных цен. Запад ограничил доступ России к финансам и технологиям, ввел санкции против энергетической, оборонной отраслей, корпораций «Роснефти», «Газпрома», ЛУКОЙЛа, «Газпром нефти», «Сургутнефтегаза» и др. Заморожены совместные проекты российских компаний с американскими и европейскими партнерами по освоению арктических нефтяных месторождений. В результате значительно уменьшилась экспортная выручка. Наглядно проявилась существенная зависимость экономики от импорта технологий, оборудования, продовольствия, потребительских товаров.

Ситуация усугубилась развернувшимся валютным кризисом в России. Давление на рубль оказали санкции, приведшие к оттоку капитала, падение цен на нефть - основного экспортного товара, срок выплаты большого корпоративного иностранного долга, отмена валютного коридора и регулярных валютных интервенций, большие социальные обязательства государства, панические настроения населения, спекулятивные действия банков. Однако для такого развития событий были и объективные предпосылки. Курс рубля во многом связан с монетарной политикой ЦБ по сжатию денежной массы. Борясь с инфляцией государство, следуя либеральным курсом, многие годы повышало процентные ставки, делая потребительский кредит малодоступным, что вынуждало российские компании брать более дешевые займы за рубежом, попадая в зависимость от иностранной валюты. В складывающейся ситуации слабый рубль усложняет обслуживание иностранных валютных кредитов, однако его укрепление может способствовать вывозу капитала, как более привлекательному вложению денег [2].

В качестве одной из главных мер по выходу их кризиса, российское Правительство выбрало политику импортозамещения, которая должна стать важным фактором экономического роста. Сегодня развитие собственного производства это не только преодоление последствий экономической изоляции, но и условие обеспечения суве- 
ренитета страны. Большая степень вовлечения в мировое хозяйство в современных политических реалиях превратилась в капкан для России, сделала ее зависимой от воли и решений партнеров. Необходима ускоренная модернизация экономики с государственной поддержкой особо значимых направлений и гарантиями для бизнеса долгосрочности этой политики.

При этом политика самообеспечения не означает самоизоляции. Россия имеет уникальное преимущество для внешних контактов, находясь между Европой и Азией, которое она пока не использовала в полном масштабе. В условиях кризиса страна заявила о развороте экономики на Восток. Но прийти на новый рынок не так просто, это работа не одного дня. Однако путь в АТР является стратегическим направлением, и упустить шанс присоединиться к этому экономическому пространству Россия не может себе позволить[5]. Российской дипломатии и бизнесу предстоит кропотливая работа по налаживанию отношений со странами Тихоокеанского региона. Наиболее сложным представляется преодоление застарелого недоверия в российско-японских отношениях, отягощенных проблемой северных территорий и поддержкой со стороны Японии западных санкций против России.

Текущий кризис имеет основания стать долгосрочным, а его последствия приведут к серьезным изменениям в мироустройстве, новым договоренностям и новой расстановке сил на мировой арене. Санкции против России не будут отменены в ближайшей перспективе. Это стратегическая цель Запада в отношении взаимодействия с Россией. Повод, выбранный ЕС для санкций - вхождение Крыма в состав России - не исчезнет никогда, значит, не исчезнут напряженные отношения. Россия не откажется от Крыма, имеющего для нее историческую и важную военно-стратегическую роль и обеспечивающего ей доминирование в акватории Чёрного и Азовского морей. Европа в свою очередь не признает легитимность его присоединения. У конфликта есть шанс перейти в вялотекущее состояние наподобие ситуации вокруг Курильских островов. При этом украинский конфликт не имеет причинного отношения к конфронтации с Россией, он лишь средство. И его разрешение не приведет к урегулированию российско-европейских отношений.
Европа, стремясь снизить зависимость от российских энергоносителей и диверсифицировать поставки, постарается решить вопрос о выходе Ирана из изоляции, что приведет к переменам на нефтяном рынке. В период нахождения Тегерана под санкциями его квота добычи нефти принадлежала Саудовской Аравии, которая должна будет уменьшить на эту величину свои объемы поставок для сохранения баланса. Различные варианты решения этого вопроса могут привести к очередным колебаниям цены на нефть и конфликту внутри ОПЕК. Однако Европу в большей степени интересует иранский газ. В этой связи есть вероятность возобновления строительства газопровода «Набукко». Но на этом пути Иран ждет противодействие со стороны США, стремящихся занять европейский рынок, что может послужить стимулом к российско-иранскому газовому сотрудничеству. Это укрепит позиции России на Ближнем Востоке, как и энергетическое сотрудничество с Турцией по строительству перенаправленного газопровода «Южный поток». Кроме того с исчезновением «иранской угрозы» появится необходимость нового обоснования развертывания ПРО в Европе, что вынудит НАТО раскрыть свои истинные цели создания противоракетного потенциала вблизи российских границ.

Однако Европа заинтересована в стабильности на континенте. И, несмотря на разногласия между Россией и Западом, ЕС придется договариваться с Россией о новой коллективной системе безопасности. Уже сейчас началась работа в рамках ОБСЕ по разработке нового соглашения «Хельсинки плюс 40», которое должно преодолеть недоверие между партнерами, усовершенствовать инструменты обеспечения безопасности и повысить эффективность сотрудничества [8].

Кризис преобразует устаревшую систему и убирает накопившиеся противоречия. Для его преодоления необходима адекватная вызовам политика государства. России предстоит обезопасить свою экономику от колебания нефтяных доходов, сделать ее менее уязвимой от международной конъюнктуры, диверсифицировать партнеров, более эффективно использовать свои ресурсные возможности, развивать нефтеперерабатывающую отрасль, экспортировать нефтепродукты.

\section{Библиография:}

1. Алхаджи А. Почему Саудовская Аравия держит низкие цены на нефть// РосБизнесКонсалтинг. - 10.03.2015. URL: http://rbcdaily.ru/economy/562949994278203

2. Глазьев С. Ошибки, которые хуже, чем преступление//Эксперт.-№44 (921).-26.10.2014. URL: http://expert.ru/ expert/2014/44/oshibki-kotoryie-huzhe-chem-prestuplenie/ 


\section{Международные отношения / International Relations / № 3 / 2015}

3. Ергин Д. Добыча: Всемирная история борьбы за нефть, деньги и власть.-М.: ДеНово, 1999.-936 с.

4. Нарочницкая Н. А. Западу не нужна Украина без Крыма// URL: http://narochnitskaia.ru/in-archive/nataliyanarochnitskaya-quot-zapadu-ne-nuzhna-ukraina-bez-kryima-quot.html

5. Никонов В.А. Подъем Азии: геополитические последствия [Электронный ресурс]// Выступление В.А. Никонова на Герцлийской конференции 2 февраля 2012 года. URL: http://www.spa.msu.ru/uploads/files/publikazii/nikonov_podjem_azii.pdf

6. Соколовская М. Лондонская нефтяная неделя// Актуальные комментарии. - 11.02.2015. URL: http:// actualcomment.ru/londonskaya-neftyanaya-nedelya.html

7. Тренин Д. В. Конец согласия: чего хочет Европа от России// РосБизнесКонсалтинг.-02.12.2014. URL: http:// rbcdaily.ru/politics/562949993171112

8. Хельсинкские соглашения 1975 года готовят к пересмотру// Газета Известия.-26.11.2014. URL: http://izvestia.ru/ news/579904

9. Chris Giles. Winners and losers of oil price plunge// The Financial Times.-15.12.2014. URL: http://www.ft.com/intl/ cms/s/2/3f5e4914-8490-11e4-ba4f-00144feabdc0.html\#axzz3UBM7HbLw

10. Nazanín Armanian. Dos objetivos del 'dumping’ del precio del petróleo. Publico.es, 17.11.2014. URL: http://blogs.publico. es/puntoyseguido/2224/dos-objetivos-del-dumping-del-precio-del-petroleo/

11. Манойло А.В. Вооруженный мятеж в Украине: волна цветных революций идет на Россию // Мировая политика. 2014. - 3. - C. 27 - 35. DOI: 10.7256/2409-8671.2014.3.11498. URL: http://www.e-notabene.ru/wi/article_11498.html

12. Иванов С.М. События на Украине и в Сирии - яркий пример политики «двойных стандартов» США // Мировая политика. - 2015. - 1. - С. 153 - 158. DOI: 10.7256/2409-8671.2015.1.12673. URL: http://www.e-notabene.ru/wi/ article_12673.html

13. Карпович О.Г. Роль культурно-цивилизационного фактора в современных международных конфликтах // Политика и Общество. - 2014. - 10. - С. 1192 - 1204. DOI: 10.7256/1812-8696.2014.10.12936.

14. Манойло А.В. Геополитическая картина современного мира и управляемый хаос // Мировая политика. - 2015. 1. - C. 66 - 80. DOI: 10.7256/2409-8671.2015.1.12665. URL: http://www.e-notabene.ru/wi/article_12665.html

\section{References (transliterated):}

1. Alkhadzhi A. Pochemu Saudovskaya Araviya derzhit nizkie tseny na neft'// RosBiznesKonsalting. - 10.03.2015. URL: http://rbcdaily.ru/economy/562949994278203

2. Glaz'ev S. Oshibki, kotorye khuzhe, chem prestuplenie//Ekspert.-№44 (921).-26.10.2014. URL: http://expert.ru/ expert/2014/44/oshibki-kotoryie-huzhe-chem-prestuplenie/

3. Ergin D. Dobycha: Vsemirnaya istoriya bor'by za neft', den'gi i vlast'.-M.: DeNovo, 1999.-936 s.

4. Narochnitskaya N. A. Zapadu ne nuzhna Ukraina bez Kryma// URL: http://narochnitskaia.ru/in-archive/nataliyanarochnitskaya-quot-zapadu-ne-nuzhna-ukraina-bez-kryima-quot.html

5. Nikonov V.A. Pod"em Azii: geopoliticheskie posledstviya [Elektronnyi resurs]// Vystuplenie V.A. Nikonova na Gertsliiskoi konferentsii 2 fevralya 2012 goda. URL: http://www.spa.msu.ru/uploads/files/publikazii/_nikonov_podjem_azii.pdf

6. Sokolovskaya M. Londonskaya neftyanaya nedelya// Aktual'nye kommentarii. - 11.02.2015. URL: http://actualcomment. ru/londonskaya-neftyanaya-nedelya.html

7. Trenin D. V. Konets soglasiya: chego khochet Evropa ot Rossii// RosBiznesKonsalting.-02.12.2014. URL: http://rbcdaily. $\mathrm{ru} /$ politics/562949993171112

8. Khel'sinkskie soglasheniya 1975 goda gotovyat k peresmotru// Gazeta Izvestiya.-26.11.2014. URL: http://izvestia.ru/ news/579904

9. Chris Giles. Winners and losers of oil price plunge// The Financial Times.-15.12.2014. URL: http://www.ft.com/intl/ cms/s/2/3f5e4914-8490-11e4-ba4f-00144feabdc0.html\#axzz3UBM7HbLw

10. Nazanín Armanian. Dos objetivos del 'dumping' del precio del petróleo. Publico.es, 17.11.2014. URL: http://blogs.publico. es/puntoyseguido/2224/dos-objetivos-del-dumping-del-precio-del-petroleo/

11. Manoilo A.V. Vooruzhennyi myatezh v Ukraine: volna tsvetnykh revolyutsii idet na Rossiyu // Mirovaya politika. - 2014. 3. - C. 27 - 35. DOI: 10.7256/2409-8671.2014.3.11498. URL: http://www.e-notabene.ru/wi/article_11498.html

12. Ivanov S.M. Sobytiya na Ukraine i v Sirii - yarkii primer politiki «dvoinykh standartov» SShA // Mirovaya politika. - 2015. - 1. - C. 153 - 158. DOI: 10.7256/2409-8671.2015.1.12673. URL: http://www.e-notabene.ru/wi/article_12673.html

13. Karpovich O.G. Rol' kul'turno-tsivilizatsionnogo faktora v sovremennykh mezhdunarodnykh konfliktakh // Politika i Obshchestvo. - 2014. - 10. - C. 1192 - 1204. DOI: 10.7256/1812-8696.2014.10.12936.

14. Manoilo A.V. Geopoliticheskaya kartina sovremennogo mira i upravlyaemyi khaos // Mirovaya politika. - 2015. - 1. C. 66 - 80. DOI: 10.7256/2409-8671.2015.1.12665. URL: http://www.e-notabene.ru/wi/article_12665.html 